International Journal of Child, Youth and Family Studies (2015) 6(1): 165-180

\title{
YOUTH WITH A DISABILITY AND THEIR EXPERIENCES WITH SOCIAL SERVICES PROGRAMS
}

\author{
James Cairns
}

\begin{abstract}
This study explored the experiences of 14 young people (aged 16 to 24) with a disability, who had accessed social services within the Greater Toronto Area (GTA) within 12 months of the dates during which the study was conducted. Through in-person and online focus groups, youth were asked to highlight their programs' positive and constructive attributes and to makes suggestions about how these services could be improved. Content analysis of the semi-structured interviews showed that on the positive side, programs offered a place to belong, an opportunity to share their feelings, and a safe space. The analysis also showed that programs could be enhanced through reducing the size of the groups and increasing the number of sessions. Suggestions for future programs were mixed with some participants preferring disability-focused groups and others preferring groups that are inclusive of all youth.
\end{abstract}

Keywords: school choice, descriptive phenomenology, parent experience with school choice, parent of a child with a disability, experiences with school choice

James Cairns, M.A. is a researcher and counsellor who is committed to providing opportunities for marginalized voices to share their experiences. E-mail: jcairns@uvic.ca 
International Journal of Child, Youth and Family Studies (2015) 6(1): 165-180

The National Centre for Health Statistics classified someone who is disabled by the following: severe limitations of daily tasks; required use of assisted devices (e.g., wheelchair); use of specialized programs or services; behavioural indications of development delay or disability; and a specific physical, mental, or emotional disability (White, 2002). This broad definition allows for the inclusion of all those that identify as disabled, and reflects the notion of a disability culture. Even individuals who have invisible disabilities (i.e., mental illness and chronic health concerns) are included in disability culture (Smith, 2009), a culture that speaks to all individuals beyond just those who have been diagnosed and supports those who have been marginalized simply by how others perceive them (Smith, 2009).

Currently there are 195,720 youth aged 15 to 24 years with a disability in Canada (Statistics Canada, 2013). Comparably, within the United States and the United Kingdom, at least one in ten children is estimated to have some form of health, developmental, and mental health concern. With these numbers, it is important that social service agencies be aware of how to properly serve youth with a disability.

Relatively speaking, the academic community appears to have ignored research on youth with a disability and their experiences with social service programs. This qualitative research study gives voice to such youth. It invited them to provide commentary on the social services that they had received and invited them to make suggestions to social service agencies who may be looking to enhance their programming and/or are planning to create new programs for this target population.

People with disabilities rely heavily on the health care system and utilize a range of health care services from therapy to community-based care (Gulley \& Altman, 2008). A study in Australia revealed that adolescents and young adults with a disability were much more likely to feel isolated from peers, excluded from employment and educational opportunities, have poorer health, and experience poverty (Emerson, Honey, Madden, \& Llewellyn, 2009).

Previous research that focused strictly on services to clients with disabilities was difficult to find. The majority of the studies focused on health care services in general. Further, these studies often focused on the many limitations and barriers that individuals with a disability face. Three identified barriers most often mentioned are: the behavior of staff towards clients, the lack of appropriate equipment, and facility location (Smith, 2009).

Where staff are concerned, participants with a disability spoke of wanting to work with staff members who present a caring and patient attitude, are tolerant of differences, and have a willingness to initiate interactions (Muller, Schuler, \& Yates, 2008). As Antle 
International Journal of Child, Youth and Family Studies (2015) 6(1): 165-180

(2004) pointed out, individuals with a disability highlighted being treated differently by staff as one of the principal issues related to their disability. Smith (2009) elaborated this finding and showed that a key barrier is the way in which staff members communicate with their disabled clients. Smith also showed that this problematic staff-to-client communication also creates communication difficulties between patients and physicians, and has been correlated with lower rates of access by disabled individuals to health care.

With regard to appropriate equipment, Smith (2009) showed that clients who are deaf have indicated the lack of text telephone (TTY) machines and/or lack of staff trained to utilize them as a communication barrier. As well, Smith noted the difficulties in locating American Sign Language (ASL) interpreters on short notice that led to difficulties in understanding physicians despite attempts at written communication.

Where facilities are concerned, Harrington and Kang (2008) showed that clients living in centralized locations were more likely to receive services. This finding echoed earlier work by Chermak (1990) who showed that centralized facilities for persons with disabilities would often target only those in their area and would exclude those outside of major urban centres. For those persons with mobility issues or illnesses that result in fatigue, this can severely compromise their attempts to attend the services (Mendelson \& Poole, 2007). Additionally, Graham and Mann (2008) found that only about 8\% of facilities they examined had an accessible bathroom and an accessible route from the entrance to main floor, lobby, and elevator thus begging the question, "If an individual with mobility issues cannot get into the building, how are they to access the services?”

Certainly, in the area of overcoming facility-related barriers some solutions have been offered. One of the solutions is utilizing a wraparound approach, which is a community-based, family driven, interagency-coordinated approach to delivering services to disabled individuals (Epstein et al., 2005). This approach could help to eliminate the facility barrier by using the school as the entry point for the delivery of services (Epstein et al., 2005). Since most young people attend school, the addition of social services within this environment could help to reduce the facility and assisted devices barriers. More solutions were highlighted that could ease facility barriers. These included ramps, repositioning furniture, Braille signage and documentation, pipe protectors, cup dispensers, and accessible paper towels (Graham \& Mann, 2008).

With regard to the barriers related to staff behaviour, Smith (2009) suggests that staff should be trained and educated to focus on a consumer drive approach while they are studying for their academic credentials. Smith suggests that thinking about clients as worthy consumers of services to whom and for whom workers are responsible, mitigates against a facility-driven mentality and forces staff to think first about adapting services to client needs, rather than forcing clients to adapt to one-size-fits-all programming. Smith also suggests that staff need to be aware that disabilities - for example, an inability to speak - does not mean that individuals have cognitive deficits, and argues persuasively that proper training can lead to the development of more programs and better customer service for those with disabilities. 
International Journal of Child, Youth and Family Studies (2015) 6(1): 165-180

Despite the progress that has been made in the area of disability studies, there are very few research studies available that focus on youth with a disability and their experiences with accessing social services. Harrington and Kang (2008), who conducted a study on the disparities in service utilization for young people with developmental disabilities (DD), related that before conducting their study they were unable to locate any previous research on this topic. Muller and colleagues (2008) also noted an absence of the voices of individuals with disabilities and have recommended that their perspectives be regularly included in any research.

With the inclusion of the voices of young people with disabilities in mind, the research study reported on here, seeks to help to fill in the present gaps in disabilities research. The central question posed by this study is: What are the experiences of youth with a disability in utilizing social services programs? This question signals a strong interest in engaging with participants' stories and therefore a qualitative approach.

\section{Methodology}

As Corbin and Strauss (2008) note, "qualitative researchers lean towards qualitative work because they are drawn to the fluid, evolving, and dynamic nature of this approach” (p. 13). Qualitative research focuses on how individuals make sense of the environments they interact with (Berg, 2007), and that was my intention where each youth in this study was concerned.

\section{Participants}

Criteria for participation in this study included: youth must be (a) between the ages of 16 and 24 years, (b) self-identified as having a disability, and (c) currently accessing or had accessed a social services program within the last 12 months in the Greater Toronto Area (GTA). Participants were 14 individuals from diverse backgrounds in terms of age, gender, disability, and type of service that they had accessed. Disabilities fell under the generalized categories of: physical disabilities, intellectual disabilities, and mental illness. Participants were recruited from various groups including: SOY Toronto, Compass group, Pathways York Region, Autism Ontario, Children's Treatment Network, and those who saw the advertised flyer at various social agencies and/or listed on social networking sites (Twitter, Facebook) and/or received the flyer by e-mail through distribution lists.

Social networking sites (i.e., Twitter and Facebook) were utilized to promote the research study. A generalized search for disability groups in Ontario was made on Facebook and information was posted on their various walls with the general information and a link to access the specific dates and locations of the focus groups. The flyer included three focus groups that individuals could participate in. It outlined that the research was being conducted by a student at Ryerson University as part of a final year research project. It stated that participants between the ages of 16 and 24 were being sought. Participants needed to identify as disabled and have utilized a social services program within the last 12 months within the Greater Toronto Area (GTA). 
International Journal of Child, Youth and Family Studies (2015) 6(1): 165-180

Once participants were selected, I elected to use focus groups rather than individual interviews because focus groups can provide insights into the experiences of people who have certain characteristics in common (Krueger, 1988). One of the benefits of conducting a focus group is the tendency to garner insights from the participants that may not occur within a one-on-one interview (Padgett, 2008; Taylor \& Bogdan, 1998). And indeed, as I gathered my data, I found that the participants were able to amplify another person's point in a way that may not have occurred within a one-on-one interview.

\section{Data Collection}

Three focus groups were spread out over a period of six weeks; they included one in-person focus group and two online focus groups. Each group had a maximum of eight registered participants to ensure that individuals would have ample opportunity to voice their opinions. The focus groups were held for a period of one hour and included 11 open-ended questions that were used to generate discussion amongst the participants. The questions were designed to gather information relating to the types of programs that participants attended, how service providers can promote their services to youth, individual experiences with accessing social services - both positive and negative - as well as soliciting feedback on the types of programs they would like to see developed in the future. Participants were also informed that they could leave if at any point they did not feel comfortable, and that they always had the right to choose not to answer the questions during the session.

The in-person focus group was hosted in a centralized location that was easily accessed by transit and that was wheelchair accessible. Participants were encouraged to show up early to review consent forms and to pose any questions they had prior to the start of the session. The session was videotaped to ensure accuracy in the collection of the data.

The other two focus groups were held online at a public website that could be accessed without the need for registration or having to download a specific chat software program. Participants could use any type of computer and browser - the only requirement was that they be able to get access to the Internet. Prior to the start of the session, participants had to review the consent form and confirm their agreement by e-mail. They were informed that the transcripts would be saved to ensure the accuracy of the data. Participants agreed to not to save a copy of the transcripts for their own purposes.

The online focus groups were chosen to create an inclusive participation opportunity for those with a disability. It had been suggested by youth and their care workers that participants with mobility issues might not be able to attend an in-person focus group. Another concern raised by participants within a group home was possible transportation difficulties. As well, individuals within the deaf community indicated that their participation would be limited without an American Sign Language (ASL) 
International Journal of Child, Youth and Family Studies (2015) 6(1): 165-180

interpreter present for the proceedings.

\section{Analysis}

After the completion of the in-person focus groups, I reviewed and transcribed the video recordings. For the online focus groups, chat sessions were continually saved and then files were added together to form a proper transcript. I used content analysis to determine the themes pertaining to the following topics: positive experiences, negative experiences, aspects of a strong program, characteristics of a good staff person, preference or otherwise for disability-focused programs, and ideal future programming ideas.

\section{Results}

\section{Attendance at Focus Groups}

The first focus group was held online and featured 4 participants. The second focus group was held in person and had 6 participants. The third focus group was held online and 4 participants were in attendance. Ages ranged from 16 to 24. Disabilities ranged from physical to intellectual disabilities and mental illness. The majority selfidentified with only one disability, although one individual did state that he had a combination of disabilities.

\section{Types of Services Accessed in last 12 Months}

Similarities became apparent, when reviewing the types of services that participants had attended. The largest majority of participants were presently accessing a weekly support drop-in program, many had attended either individual or group counselling, one participant was involved in an anger management program, one was presently in a group home, one was attending a school for the deaf, and two were involved in youth-specific recreational programs.

\section{Positive Aspects of Programs}

The question was posed to each individual about the positive aspects that each program offered them. Three themes became apparent from the participants' reponses: a place to belong, the opportunity to share their feelings, and a safe space. An online participant stated that their involvement "enables me to feel more involved in my community". Many other participants echoed this sentiment, noting that they had felt isolated prior to joining their respective programs/services. The positive aspect of the space being safe and non-judgmental was brought up within each focus group. Many youth expressed having been teased and/or made fun of at school and even within their own families, but felt safe within their groups. "Often, I get, made fun of, but here we joke around and it's not in a mean way" summed up one online participant describing their weekly program. In their respective programs, they had the opportunity to express 
International Journal of Child, Youth and Family Studies (2015) 6(1): 165-180

these feelings and discuss possible solutions to solving it. "I spend my time away from the program waiting the opportunity to get back to it. Here, I feel welcomed and have friends that care" shared a participant from the in-person focus group.

\section{Suggested Improvement for Programs}

To ensure the accuracy of assessments about the programs, the participants were asked if there were any improvements that could be made to their programs. Two themes were mentioned clearly by a majority of the participants: the size of the group and the length of the programs. Participants felt that in an effort to reach more youth, many of their programs accepted too many participants and it was causing them to be less effective. An individual within a group home stated, "Eight kids in a four-bedroom house means shouting and screaming every day", while another youth found that "the group can't tap into everyone's potential when there's too many people in a room”. The underlying reasoning behind limited group size appeared to be that individual attention is needed and that it is easier to control a small group.

Length of the program was continuously brought up within the different groups as many felt that programs were too short of time and/or had too few sessions. The norm appeared to be one hour a week for four to six sessions, with a lengthy break before another session would open up again. Participants expressed the need for lengthier sessions that could possibly continue year round: "u finally feel comfortable and willing to share and then it's over until next year” [error in original] was one participant's comment over his dismay at the short length of the program.

\section{Promotion of Programs}

Participants found out about their programs through assigned care professionals (i.e., social worker, community worker, youth worker, or guidance counsellor), family members, word of mouth through friends, social networking sites, and through their own online searches. Word of mouth played a key part in them discovering new programs and was the best indicator that they would go to the program.

These methods are similar to their suggestions to social service agencies for promoting their programs to youth. Getting the information to the schools was another main factor with one student pointing out that, "The best way for agencies to get their programs known is through the school, since youth are at school for seven hours! This means that they should not just vaguely remind a guidance counsellor about their services but also send posters, brochures, and representatives.”

\section{Types of Programs that Interest Youth}

When asked about the attributes of a program that is attractive to youth, there were four core themes that emerged: development of skills, the accessibility of location, day and time of the program, and the organization of session(s). Youth were looking for a program that would assist them with leadership and life skills: "i wnt to improve my 
International Journal of Child, Youth and Family Studies (2015) 6(1): 165-180

skills n find a way to get smarter at real stuff” [error in original]. Youth highlighted how programs that involved opportunities for discussion and instructional hands-on activities were the most desirable. Along with this, the sessions should be organized and a purpose should be evident each week.

Accessibility of the location and program was a high indicator of potential attendance for these participants. This included having buildings that were close to transit systems or within walking distance of their homes: "more than 30 minutes away and I won't be going to a program and not in a sketch area” stated one of the online participants. The single deaf participant in the study, who was involved in one of the online focus groups, wished that services could be expanded to online forums stating that, "I kinda wish all things could just be online. I get excluded from a lot due to ASL interpreter costs”.

\section{Preferred Characteristics of Staff}

The staff are a key component in each program/service that the participants were involved in and the characteristics that they sought out in the staff included: being accepting of others, being organized, not a dictator, punctual, real (not fake), respectful, treats us like adults, willing to hear suggestions, friendly, not condescending, but cool and welcoming. Youth stated that staff were their main reason for continuing or discontinuing a program. One online participant offered a piece of advice for all service providers: "people need to realize that they can't fix everything, even if they're really good at what they do".

\section{Ideal Future Programs}

There was a split in each group over whether they would prefer a program that catered to their specific disability or was open to all youth. The replies ranged from those in favour of programs exclusive to one disability ("I feel safer with those that have the same problems as me") to a more inclusive program ("I prefer programs that are INCLUSIVE to all" [emphasis in original]). One individual shared that, "I actually feel kind of awkward in disability-focused spaces in real life because I don’t appear disabled”.

The main themes most prevalent with respect to what characteristics an ideal program would include: friendly staff, incentives (i.e., free food and TTC tokens), and that youth input was sought to reflect the programming. With incentives came the statement that there should be "more positive encouragement (why do we always lose rights/privileges)". On the topic of friendly staff, one participant made the following observation: "follow through! if you say you'll do something, then do it. or say you're sorry when u f it up" [error in original]. Finally youth input/inclusion can be summed up by the following comment: "I would like to see that every participant has an equal opportunity to participate and have leadership roles in the program, regardless of the length of their commitment (e.g., how long they have been a part of the program), ethnicity, or gender". 
International Journal of Child, Youth and Family Studies (2015) 6(1): 165-180

These results demonstrate that youth with a disability were able to strongly articulate their experiences of accessing social services programs. A review of the literature, in light of these results, permits an in-depth discussion of this topic.

\section{Discussion}

Given the limited number of studies about the experiences of youth with a disability in social services programs, I believe this study has a useful contribution to make. I also believe that it is important to first acknowledge the 14 participants for their contribution and to note that these individuals were speaking for themselves and not for the disabilities that they have. Nevertheless, with the limited access to these kinds of studies, this information should be viewed as a valuable critique of the programs that are being offered to such young people at this time. All of the participants were recent or current attendees at various types of social services programs within the GTA within the last 12 months. They are therefore able to judge what is presently out there and are in a unique position to offer honest feedback on the positive and negative aspects of these services, while also suggesting how to improve programs for current and future participants.

Many of the service limitations described in the literature review were highlighted again in the findings of this study. The most pressing issues that were identified focused on the facility (i.e., physical barriers, location of facility, and lack of proper equipment), the staff of the programs, and the lack of promotion of the programs to a wider area. For many of the participants the need for services that are within walking distance and/or easily accessible by transit was identified as their number one priority. This confirms earlier findings by Harrington and Kang (2008) who showed that individuals in centralized locations had more access to services, and also supports the findings of Mendelson and Poole (2007) who showed that many individuals with mobility issues were unable to access services.

The lack of proper supportive equipment was also identified as a barrier. For example, as a deaf participant explained, many programs do not provide an ASL interpreter. This confirms the research of Smith (2009) who examined patient-physician communication and also found that for deaf patients the lack of effectively trained staff to handle their needs was a barrier.

Providing ASL interpreters would require an organizational change in the process of putting together a social services program. It may require putting requests for these kinds of funds into present application grants or applying for new grants with a specific focus on increasing accessibility through the offering of ASL interpreters. Whether or not this is feasible for a small agency is an open question. One option that may help with keeping services affordable is the online option and the agencies may want to offer online communications for their clients and staff. It could well save on costs with respect to renting space and ensuring buildings are accessible, if clients only require the use of a computer with an Internet connection. 
Previous studies (Antle, 2004; Muller et al., 2008; Smith, 2009) also highlighted that their participants wanted to encounter staff who are respectful, caring, organized, and sought input from the youth. These general qualities may seem simple, but could make the difference between a successful program and one that falls flat. Participants really highlighted their need to be listened to and respected by the staff. This could be related to the sense that sometimes being disabled means that one is treated differently or is perceived to be less of a person.

If staff fails to seek their active input around programs, numerous disabled youth may be left out of those programs. As previously noted by Emerson et al. (2009), this could amplify feelings of isolation, as many do not feel like a significant member of the community. These skills will need to be taught at the educational institutions that train staff. If such training is not included by institutions that educate those who work with disabled youth, it should at least be offered as part of the training for new staff within every agency. Disabled youth need to be engaged to the same degree as any other youth who are participating in a program.

Another similarity to previous studies that was presented in this current one was the idea of promoting services to all youth and not just those in the general vicinity of their service locations. Chermak (1990) found that centralized locations would often only target those in the immediate vicinity and exclude those outside of the area. Youth brought up the idea of promoting directly to schools through flyers and announcements to ensure that the word got out to everybody and not just their guidance counsellors. They highlighted the importance of utilizing social networking sites (e.g., Facebook and Twitter) to help spread the word and that these tools could be utilized to support word of mouth information. Distribution lists, word of mouth, and social networking sites were the principal tools used in this study. Not a single participant mentioned seeing a flyer about the focus groups, but instead highlighted that they had received a notice by e-mail, saw it on Facebook, or heard about it through a social services worker or a friend. Social service agencies should consider the potential of new technologies as a key way to promote their services.

Social networking sites are free options that could be easily pursued in promotion or as a supplement to current promotional efforts. Pamphlets, flyers, and brochures may soon become a thing of the past and agencies should embrace this technology. Those with physical impairment may already have enhancements on their computer screens and this would cut down on the costs of trying to produce accessible literature. For example, an individual with a visual impairment would require a flyer specifically created for their needs that could come at a substantial cost. Those with a computer with screen reader technology would be able to access an online site and utilize their own technology to receive the information at no extra cost to the service agencies.

Incentives were a new idea that was generated through the focus groups as an aspect of an ideal program. This information could also be utilized in future studies on this topic. As there were no incentives offered within the focus groups, this could have limited the interest of the target population. The suggestions regarding incentives that 
came from the group included having food available, providing transit tokens, and financial rewards for continued participation. If such items are not present in current program plans and/or budgets, these should be items that staff pursues in the future.

Ward (2003) stated that having a disabled researcher included in the research team could lead to more successful studies. None of the youth brought this up as a factor that influenced their decision to participate in the focus groups. Perhaps that was because the information about the study that they received was presented via e-mail distributions and Facebook notes. Nonetheless, the participation of a disabled researcher in any face-toface engagement with participants should not be underestimated and could certainly be considered as important in any research and program design and delivery.

The idea of having disability-specific youth social services versus being inclusive to all youth stimulated an interesting discussion within each focus group. Participants seemed divided between wanting to be inclusive of everybody and still having a safe space to communicate their individual needs. One individual stated that due to the lack of visibility around their disability, they felt uncomfortable in situations that were more generally inclusive.

The need for more education about the distinctions, differences, and shared experiences of persons with disabilities was reflected when several participants contacted me about whether they fit into these focus groups as disabled people. For this study, the only requirement was that they self-identified as disabled; however, some participants still worried about whether this requirement applied to them. This suggests that agencies and service providers could take the opportunity to begin to initiate and educate around a different view of what a disabled person is and thereby assist those who are disabled in feeling less isolated from the general community. A broader understanding of persons with disabilities could help people to realize that more people than not have some sort of disability.

Agencies may also want to consider the images they are utilizing when promoting their services and how they themselves have described being disabled in their own literature. Not everyone with a disability uses a wheelchair, a guide dog, or has a particular physical appearance. Many have invisible disabilities that are not apparent to others and this could lead to a degree of friction within a group. Properly educating staff and participants on the variety of disabilities that exist could prove to be a valuable component of training.

Additionally, agencies may want to decide if there is value in catering to specific disabilities or simply ensuring that their programs are truly inclusive to all. If the programs are to be inclusive, are their proper supports in place to ensure that anybody can truly access their services? Having a disability-specific group could assist youth with connecting with other youth that share similar disabilities. This could well buttress a supportive group environment, where individuals could learn from each other's experiences. 
International Journal of Child, Youth and Family Studies (2015) 6(1): 165-180

Where an all-inclusive group could be just as effective, especially within a skillsbased program, staff should be challenged to ensure that the skills could be taught to different levels of ability. This would ensure that an agency's staff are catering to a large representation of the youth population, while participants could greatly benefit from having the opportunity to connect with youth from diverse backgrounds.

\section{Limitations}

One limitation of this study, and for that matter of any study based on focus group data, is the extent to which group-think may affect individual responses (Kidd, 2000; Mansell, Bennett, Northway, Mead, \& Moseley, 2004). Within any focus group and especially with this target age, participants could be susceptible to trying to please either those in the group or the researcher leading the activity. Still the anonymity that accompanied the online focus groups could have encouraged them to voice their own opinions and not those of the other individuals. As well, a majority of the participants were involved in weekly group programs and this could have had an impact on the results. Because so few of the participants were involved in one-on-one therapies within or outside a residential setting, the findings of this study cannot properly represent their experiences. Rather, these findings are a general commentary on social services as a whole that do not speak specifically to each service or program.

\section{Further Research}

With the potential implications and limitations described above in mind, further research could be conducted to determine whether the suggestions given by the participants would create a more effective program for youth that self-identify as disabled. Partnerships could be developed with agencies that are presently serving or are interested in serving this target population. These agencies could review their present practices and implement the feedback on location, staff, and what an ideal program might entail.

For data collection in subsequent studies, it may be wise to do a survey with the option of following up with select participants. Despite promotional efforts that included a number of service agencies sending out notices, posting flyers, and the use of social networking sites to get the word out over a period of three months, this study only managed to attract 14 participants. The time commitment and youth's busy schedules may explain the low participant response to involvement that required participation in a focus group. A survey, on the other hand, could be distributed through the same channels that were utilized to advertise the focus groups and could be completed at the convenience of respondents.

Four social services programs did not choose to distribute the information that invited their clients to participate in the study. One group refused to share the focus group with the participants due to the fear that their clients would be incapable of answering the questions for the focus group. The suggestion of altering the questions to fit their mental capacity was met with resistance. The other three all returned with the statement that they 
International Journal of Child, Youth and Family Studies (2015) 6(1): 165-180

were presently all booked up and/or too busy at the present time. The option of completing a survey would have solved the "too busy" issue. As well, this may demonstrate that a study of this kind requires more than three months notice to put together. Social agencies should be contacted at least six months in advance.

The online focus groups seemed to attract more youth than the face-to-face option and this could be due to the anonymity of the Internet. Filling out an online survey could provide a further sense of anonymity and allow participants to feel even more at liberty to share their thoughts and feelings. During the in-person focus group, the youth took longer than the online group participants to start sharing their thoughts and feelings. It was only within the final 30 minutes that they began to offer more of their thoughts and feelings while starting to acknowledge what other participants were saying.

If focus groups were utilized again, incentives should be provided. Incentives may include: free food, transit tickets to get to and from the venue, and even the opportunity to earn a prize for participation. Attracting youth could be made easier if there's a reward in it for them. For this study, the only reward was the opportunity to share their thoughts in the hope that programs could become more accessible in the future. This intangible gift may be less valuable to them than something as tangible as a gift card.

Finally, expanding the target population could help to increase the number of respondents. In future research, the age range could include 16- to 24-year-old participants, plus those closest to these participants or their programs such as the parents of disabled youth, social service providers, and educators. Each of these groups could add value to the study by sharing their experiences of trying to get or provide accessible and successful programs for the youth.

Moreover, in an effort to expand the target population, additional research could include self-identified disabled youth who have never accessed a social service program or those who had attended a program outside of the previous 12 months. Having participants who had never accessed programs involved in research could generate a different view of what is lacking in the present services being offered. Those who had accessed a program more than 12 months ago could explain why that is, and thus could offer valuable information for the service agencies on how to retain this population.

Further research could also be focused on determining the amount of access disabled youth presently have to new technology. Do they have a computer? Do they have a screen reader for their computer? While the online focus groups tended to generate more participation in the present study, this could have been a serious limitation to youth without access to technology. Including an inquiry into youth's access to technology in a further study would significantly help, especially in the financial area. If a significant proportion of individuals have access to technology, it could assist in the creation of programs that do not require space, inclusion facilitators, modified equipment, and/or ASL interpreters. 
International Journal of Child, Youth and Family Studies (2015) 6(1): 165-180

\section{Conclusion}

This study is a small step toward documenting the experiences of youth with a disability who utilize social services programs within the GTA. While only a small number of youth participated, we should not discount their opinions on the state of the programs that they have accessed. Youth programming exists in an ever-changing milieu and knowing what young people think and need is key to building a successful program. The findings of this study give service providers an opportunity to reflect on the programs that are presently offered and suggest ways that they can enhance them. Those agencies that have been hesitant to target this market with their programs have now been given some basic ideas on how to do so. None of these youth were asking for drastic changes to the present system that exists within the GTA. An ideal program, simply put, includes incentives, friendly staff, and involving youth input. None of these add great expenses to any programs currently being offered. One hopeful and helpful outcome of this study is that simple shifts in thought, attitude, and behaviour have the potential to accomplish a great deal of good. 
International Journal of Child, Youth and Family Studies (2015) 6(1): 165-180

\section{References}

Antle, B. J. (2004). Factors associated with self-worth in young people with physical disabilities. Health \& Social Work, 29(3), 167-175. http://dx.doi.org/10.1093/hsw/29.3.167

Berg, L. B. (2007). Qualitative research methods for the social sciences (6th ed.). Toronto: Pearson Education, Inc.

Chermak, G. D. (1990). A global perspective on disability: A review of efforts to increase access and advance social integration for disabled persons. International Disability Studies, 12(3), 123-127. http://dx.doi.org/10.3109/03790799009166266

Corbin, J., \& Strauss, A. (2008). Basics of qualitative research (3rd ed.). London: Sage Publications, Ltd. http://dx.doi.org/10.4135/9781452230153

Emerson, E., Honey, A., Madden, R., \& Llewellyn, G. (2009). The well-being of Australian adolescents and young adults with self-reported long-term health conditions, impairments, or disabilities: 2001 and 2006. Australian Journal of Social Issues, 44(1), 39-53.

Epstein, M. H., Nordness, P. D., Gallagher, K. J., Nelson, R., Lewis, L., \& Schrepf, S. (2005). School as the entry point: Assessing adherence to the basic tenets of the wraparound approach. Behavioural Disorders, 30(2), 85-93.

Graham, C. L., \& Mann, J. R. (2008). Accessibility of primary care physician practice sites in South Carolina for people with disabilities. Disability \& Health Journal, 1(4), 209-214. http://dx.doi.org/10.1016/j.dhjo.2008.06.001

Gulley, S. P., \& Altman, B. M. (2008). Disability in two health care systems: Access, quality, satisfaction, and physician contacts among working-age Canadians and Americans with disabilities. Disability and Health Journal, 1(4), 196-208. http://dx.doi.org/10.1016/j.dhjo.2008.07.006

Harrington, C., \& Kang, 'I.' (2008). Disparities in service utilization and expenditures for individuals with developmental disabilities. Disability \& Health Journal, 1(4), 184-195. http://dx.doi.org/10.1016/j.dhjo.2008.05.004

Kidd, P. S. (2000). Getting the focus and the group: Enhancing analytical rigor in focus group research. Qualitative Health Research, 10(3), 293-308. http://dx.doi.org/10.1177/ 104973200129118453

Krueger, R. A. (1988). Focus groups: A practical guide for applied research. Thousand Oaks, CA: Sage Publications.

Mansell, I., Bennett, G., Northway, R., Mead, D., \& Moseley, L. (2004). The learning curve: The advantages and disadvantages in the use of focus groups as a method of data collection, Nurse Researcher, 11(4), 79-88. http://dx.doi.org/10.7748/nr2004.07.11.4.79.c6217

Mendelson, C., \& Poole, J. L. (2007). Become your own advocate: Advice from women living with scleroderma. Disability and Rehabilitation, 29(19), 1492-1501. http://dx.doi.org/10.1080/09638280601029480 
International Journal of Child, Youth and Family Studies (2015) 6(1): 165-180

Muller, E., Schuler, A., \& Yates, G. B. (2008). Social challenges and supports from the perspective of individuals with Asperger syndrome and other autism spectrum disabilities. Autism, 12(2), 173-190. http://dx.doi.org/10.1177/1362361307086664

Padgett, D. K. (2008). Qualitative methods in social work research (2nd ed.). New York: Sage Publications.

Smith, D. L. (2009). Disparities in patient-physician communication for persons with a disability from the 2006 medical expenditure panel survey (meps). Disability \& Health Journal, 2(4), 206-215. http://dx.doi.org/10.1016/j.dhjo.2009.06.002

Statistics Canada. (2013). Canadian survey on disability. Retrieved from http://www.statcan.gc.ca/pub/89-654-x/89-654-x2013001-eng.pdf

Taylor, S. J., \& Bogdan, R. (1998). Introduction to qualitative research methods: A guidebook and resource (3rd ed.). Toronto: John Wiley \& Son, Inc.

Ward, M. (2003). The views of people with a physical disability on day activity centres in the eastern region of Ireland. Disability and Rehabilitation, 25(10), 527-531. http://dx.doi.org/10.1080
/0963828031000090399

White, P. (2002). Access to health care: Health insurance considerations for young adults with special health care needs/disabilities. Pediatrics, 110(6), 1328-1335. 